\title{
Evolution of aortic wall thickness: long-term follow up from the Multi-Ethnic Study of Atherosclerosis (MESA)
}

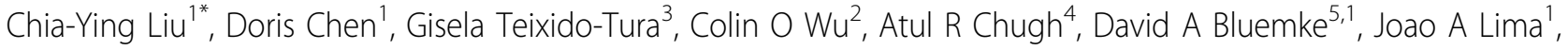 \\ W Gregory Hundley ${ }^{6}$
}

From 16th Annual SCMR Scientific Sessions

San Francisco, CA, USA. 31 January - 3 February 2013

\section{Background}

A number of studies have been published over the years concerning the relationship between the thickened intima of human arteries and atherogenesis. Increased arterial wall thickness is associated with the prevalence and incidence of cardiovascular disease. Age-related increases of aortic wall thickness have been reported in several crosssectional community-based studies. However, longitudinal changes of these measurements have not yet been documented. The purpose of this study is to characterize ageand sex-specific aortic wall thickness (AWT) distributions and yearly rates of change in older adults.

\section{Methods}

371 longitudinal and 426 cross sectional studies with AWT images by MRI were analyzed. MRI was performed at first in MESA1 (baseline, 2000-2001), and then in MESA5 (ten-year follow-up, 2010-2011). Both exams used 1.5-T whole-body MRI systems. Images were obtained using a double inversion recovery blackblood fast spin-echo sequence with ECG gating. Axial images of the descending thoracic aorta were obtained at the level of the right pulmonary artery. The thickness of the midthoracic descending aortic wall was measured using electronic calipers at 4 standard positions: $12,3,6$,

Table 1 Mean characteristics of the MESA5 participants

\begin{tabular}{|c|c|c|c|c|}
\hline At MESA5 (2010-2011), mean \pm SD & GLOBAL (N=426) & Women $(\mathrm{N}=245)$ & Men $(\mathrm{N}=181)$ & p-value \\
\hline Age (years) & $70.8 \pm 8.7$ & $70.9 \pm 8.9$ & $70.5 \pm 8.5$ & 0.64 \\
\hline Race (N of white/black) & 259/167 & $144 / 101$ & $115 / 66$ & 0.27 \\
\hline Body mass index (kg/m2) & $28.7 \pm 5.3$ & $28.7 \pm 5.9$ & $28.3 \pm 5.3$ & 0.45 \\
\hline Systolic blood pressure (mmHg) & $125 \pm 21$ & $125 \pm 21$ & $124 \pm 21$ & 0.68 \\
\hline Diastolic blood pressure $(\mathrm{mmHg})$ & $68 \pm 10$ & $65 \pm 10$ & $71 \pm 10$ & $<0.001$ \\
\hline Metabolic Syndrome, N (\%)* & $146(34.3)$ & $96(39.2)$ & $50(27.6)$ & 0.02 \\
\hline LV End diastolic volume (ml) & $120 \pm 31$ & $106.2 \pm 23$ & $138.4 \pm 31$ & $<0.001$ \\
\hline LV End systolic volume (ml) & $47 \pm 18$ & $38.5 \pm 12$ & $57.5 \pm 20$ & $<0.001$ \\
\hline LV End diastolic mass (g) & $125 \pm 35$ & $105.4 \pm 22$ & $152.2 \pm 32$ & $<0.001$ \\
\hline LV Stroke volume (ml) & $73.2 \pm 18$ & $67.7 \pm 16$ & $80.9 \pm 18$ & $<0.001$ \\
\hline LV Ejection Fraction (\%) & $61.8 \pm 7.2$ & $63.9 \pm 6.7$ & $58.9 \pm 7$ & $<0.001$ \\
\hline Aortic wall thickness (mm) & $2.67 \pm 0.27$ & $2.61 \pm 0.26$ & $2.75 \pm 0.26$ & $<0.001$ \\
\hline Wall thickness difference in ten years ( $\mathrm{mm})$ & $0.32 \pm 0.46$ & $0.30 \pm 0.44$ & $0.35 \pm 0.48$ & 0.26 \\
\hline
\end{tabular}

* Metabolic Syndrome was defined by NCEP guidelines (Circ 2004;109;433-438)

'Department of Radiology, Johns Hopkins University, Baltimore, MD, USA

Full list of author information is available at the end of the article

(c) 2013 Liu et al; licensee BioMed Central Ltd. This is an Open Access article distributed under the terms of the Creative Commons 


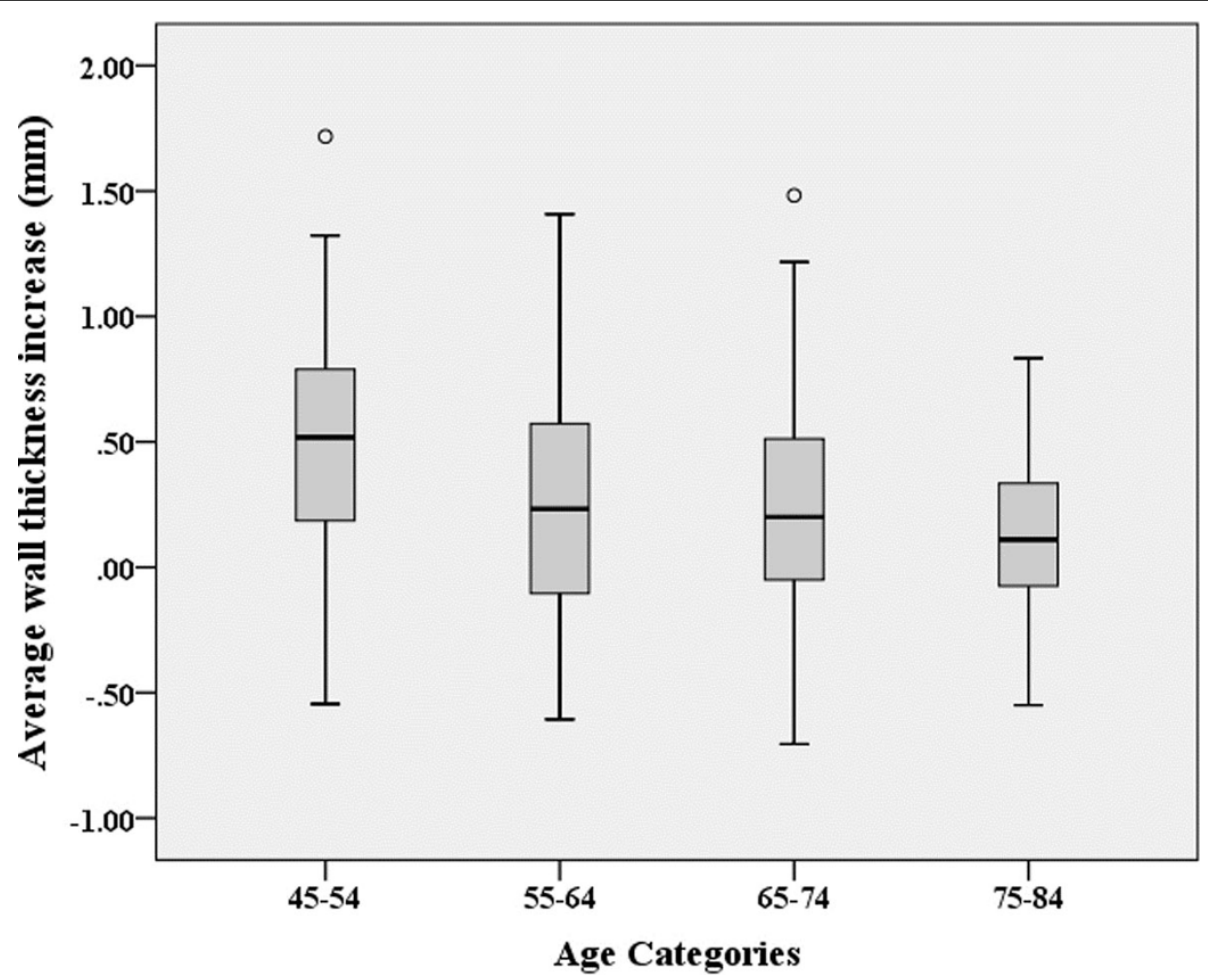

Figure 1 Average aortic wall thickness increase in ten years by age categories (in the baseline age).

and 9 o'clock (QMASS 7.2). The average value of these 4 measurements was calculated.

\section{Results}

Table 1 lists demographics and AWT in MESA5 (20102011), and changes of AWT in ten years stratified by gender. AWT and cardiac function were significantly different between men and women. Changes of AWT were greater for men than women, but not significant. The average yearly rate of AWT change was $0.032 \mathrm{~mm}$. Figure 1 displays the average AWT increase in ten years by age categories (in the baseline age). AWT increased more markedly in mid-adulthood, and was plateaued over time into lateadulthood ( $\mathrm{p}$-trend $<0.001$ ). Framingham global CVD risk score assessed at the baseline was positively correlated with the AWT measured in MESA5 ( $\mathrm{R}=0.261, \mathrm{p}<0.001)$.

\section{Conclusions}

We report aortic wall thickness changes over mid to late adulthood in longitudinal comparisons. Further analyses will reveal the correlates of these alterations with clinical variables.

\section{Funding}

N01-HC-95168 from the National Heart, Lung, and Blood Institute.

\section{Author details}

'Department of Radiology, Johns Hopkins University, Baltimore, MD, USA. ${ }^{2}$ Office of Biostatistics Research, National Institutes of Health, Bethesda, MD, USA. ${ }^{3}$ Department of Cardiology, Hospital General Universitari Vall dHebron, Barcelona, Spain. ${ }^{4}$ Division of cardiovascular medicine, University of Louisville School of Medicine, Louisville, KY, USA. ${ }^{5}$ Radiology and Imaging Sciences, National Institutes of Health, Bethesda, MD, USA. ${ }^{6}$ Division of Cardiology, Deparment of Internal Medicine, Wake Forest University, Winston-Salem, NC, USA

Published: 30 January 2013

doi:10.1186/1532-429X-15-S1-M14

Cite this article as: Liu et al:: Evolution of aortic wall thickness: longterm follow up from the Multi-Ethnic Study of Atherosclerosis (MESA). Journal of Cardiovascular Magnetic Resonance 2013 15(Suppl 1):M14.

Submit your next manuscript to BioMed Central and take full advantage of:

- Convenient online submission

- Thorough peer review

- No space constraints or color figure charges

- Immediate publication on acceptance

- Inclusion in PubMed, CAS, Scopus and Google Scholar

- Research which is freely available for redistribution 